\title{
BMJ Open Evaluation of the alignment of policies and practices for state-sponsored educational initiatives for sustainable health workforce solutions in selected Southern African countries: a protocol, multimethods study
}

\author{
Sikhumbuzo Mabunda (D) , ${ }^{1}$ Blake Angell (I) , ${ }^{1,2}$ Rohina Joshi (I) , ,,3 \\ Andrea Durbach ${ }^{4}$
}

To cite: Mabunda S, Angell B, Joshi R, et al. Evaluation of the alignment of policies and practices for state-sponsored educational initiatives for sustainable health workforce solutions in selected Southern African countries: a protocol, multimethods study. BMJ Open 2021;11:e046379. doi:10.1136/ bmjopen-2020-046379

- Prepublication history and additional supplemental material for this paper are available online. To view these files, please visit the journal online (http://dx.doi.org/10.1136/ bmjopen-2020-046379).

RJ and $A D$ are joint senior authors.

Received 28 0ctober 2020 Revised 17 February 2021 Accepted 30 March 2021

Check for updates

(c) Author(s) (or their employer(s)) 2021. Re-use permitted under CC BY-NC. No commercial re-use. See rights and permissions. Published by BMJ.

For numbered affiliations see end of article.

Correspondence to Dr Sikhumbuzo Mabunda; drskhumba@gmail.com

\section{ABSTRACT}

Introduction Health systems across the world are facing challenges with shortages and maldistribution of skilled health professionals. Return-of-service (ROS) initiatives are government-funded strategies used to educate health professionals by contracting beneficiaries to undertake government work on a year-for-year basis after their qualification. It is envisaged that once they have served their contract, they will be attracted to serve in the same area or government establishment beyond the duration of their obligatory period. Little is known about the processes that led to the development and implementation of ROS policies. Furthermore, there is no systematic evaluation of the strategies that demonstrate their utility. This research aims to evaluate the ROS initiatives, explore their efficacy and sustainability in five Southern African countries.

Methods and analysis This study will be conducted in South Africa, Eswatini, Lesotho, Botswana and Namibia in a phased approach through a multimethods approach of policy reviews, quantitative and qualitative research. First, a review will be conducted to explore current ROS schemes. Second, a quantitative retrospective cohort study of ROS scheme recipients for the period 2000-2010 will be undertaken. Information will be sourced from multiple provincial or national information systems and/ or databases. Third, we will conduct semistructured group or individual interviews with senior health, education, ROS managing agency managers (where appropriate) and finance managers and/policy makers in each country to determine managers' perceptions, challenges and the costs and benefits of these schemes. Fourth, we will interview or conduct group discussions with health professional regulatory bodies to assess their willingness to collaborate with ROS initiative funders.

Ethics and dissemination Ethics approval for this study was obtained through the Human Research Ethics Committees of the University of New South Wales (HC200519), Australia; South Africa and Lesotho (065/2020); Eswatini (SHR302/2020); Namibia (SK001); and Botswana (HPDME 13/18/1). Relevant findings will be shared through presentations to participating
Strengths and limitations of this study

- This is the first study to concurrently assess returnof-service (ROS) scheme policies, measure attainment of policy outcomes, evaluate perceptions of those who administer the scheme and identify possible solutions for the enhancement and reformulation of the schemes.

- The multimethods design and triangulation of information sources underlying this research provides a unique opportunity to gain a deep insight into ROS schemes and their capacity for sustainable global health workforce solutions.

- Given this study is being conducted during the global COVID-19 pandemic by global researchers in five countries when global travel is restricted, it presents an opportunity for the development of innovative methods to engage with stakeholders and collect data remotely.

- It is anticipated that the study will be limited by nonavailability or poor information systems and low quality of the available information.

- If ROS schemes are viable strategies for increasing the pool of skilled health professionals, information systems will need to be significantly improved that will in itself be an important outcome of the study.

governments, publications in peer-reviewed journals and presentations at relevant conferences.

\section{INTRODUCTION}

The WHO characterises a health system as consisting of six building blocks: leadership and governance; human resources for health; medical products, vaccines and technologies; information and research; service delivery platform; and health financing. ${ }^{1-4}$ Notwithstanding, human resources for health (HRH) act as the key stimulant of the health system, 
without which health delivery and access is severely impeded. The performance of a health system is therefore reliant on the production, distribution and retention of $\mathrm{HRH}^{45}$

The maldistribution of skilled health professionals (SHPs) within and across countries results in poorly functioning services and inequity in access to healthcare especially in low-income and middle-income countries where there is a particular shortage of SHPs. ${ }^{4}$ Although the WHO estimates the need for a minimum of 45.5 physicians, nurses and midwives per 10000 population, sub-Saharan Africa (SSA) has only 12.2 physicians, nurses and midwives per 10000 population. ${ }^{6-8}$ While countries like South Africa seem better off with 9.05 physicians per 10000 population compared with the SSA average (2.34) and countries like Lesotho (0.69), Eswatini (3.29), Namibia (4.18) and Botswana (5.27), South African physicians are not equitably distributed with rural and poorer areas chronically underserviced by SHPs. ${ }^{67}$

It has been estimated that despite the fact that $44 \%$ of the South African population live in rural areas, they are served by $12 \%$ of doctors. ${ }^{46-11}$ Several strategies have been used to try and address this maldistribution in Southern African countries. These include: (1) financial incentives (rural allowance, scholarships and loan repayment schemes); (2) educational strategies (targeted admission policies for medical schools, undergraduate and postgraduate training exposure and the location of medical schools in rural areas and/or the inclusion of rural training programmes); (3) personal and professional support; and (4) regulatory strategies. ${ }^{4-11}$

State-sponsored educational initiatives are strategies that combine the training of aspiring health professionals with government human resources recruitment and retention strategies. ${ }^{4}{ }^{12-16}$ Also known as returnof-service (ROS) schemes, these strategies award a study scholarship or bursary to health sciences students in return for a commitment to serve government on a year-for-year reciprocal contract after completion of their studies. ${ }^{4{ }^{12-16}}$ Some ROS schemes have a financial option for beneficiaries who do not fulfil their contractual obligations. ${ }^{16} 17$ The primary objective is to increase the pool of health professionals in a defined area and/ or government service for a set number of years. ${ }^{4512-16}$ The secondary objective is to retain these health professionals in the same area of their service beyond their obligatory service period. ${ }^{4512-16}$ Candidates are chosen by reference to their socioeconomic status, school grades, career choice of study and whether they are from a rural setting and a low quantile school. ${ }^{4}$ Historically, Eswatini, Lesotho, Botswana and Namibian governments would send health sciences students to study in South African medical schools. Botswana and Namibia have since started training their own medical students with the opening of medical schools in 2009 and 2010, respectively.

The extent to which policy makers review and systematically evaluate the implementation of these strategies is unclear. In addition, although these strategies have been designed to address health workforce shortages and maldistribution, their development appears to lack a basis in evidence-based policies, nor is there clear evidence of consideration of other factors likely to be vital to the success of such policy initiatives. ${ }^{4}$ These include a lack of monitoring and evaluation capacity within administrating institutions (including clear plans for review) and the impacts of interactions between different stakeholders, that is, the training institutions or countries, students, SHPs, regulatory bodies and health facilities. ${ }^{4}$ Ideally, ROS policies should be one part of a broader package of initiatives designed to serve as a catalyst for creating a supportive environment for health professionals that build on and reinforce each other; yet, once again, the extent to which this is occurring is unclear. ${ }^{4} \mathrm{~A}$ further potential weakness of these strategies is that anecdotal evidence (based on the researcher's personal communications with beneficiaries of state sponsored educational initiatives) suggests that some graduates do not fulfil their contractual obligations by serving their governments for an equivalent number of years as equivalent to the duration of the funding assistance received nor do they pay financial compensation in lieu of their service, if this is the requirement. By contrast, some studies indicate that most ROS beneficiaries fulfil their contractual obligation; their retention beyond their contractual obligation is less successful. ${ }^{1216}$ Furthermore, in many cases, there appears to be a potential lack of consideration for the future financial capacity required to pay the future salaries of all graduates from these schemes, suggesting that the health system may not be able to ultimately benefit from ROS beneficiaries as initially planned. ${ }^{45}$

The shortages and maldistribution of health professionals is a complex problem needing innovative, sustainable and efficient solutions. ${ }^{4}$ Despite the wide use of these educational initiatives across the world (and associated investment of scarce healthcare resources), there is limited literature to guide policy makers deciding whether to introduce or continue ROS schemes or on identifying components of the schemes essential to their success. No published literature was found assessing the evolution or formulation of these policies, their impact, successes and challenges nor any systematic investigation of the perceptions of managers and policy makers. Similarly, the relative resource use implications of these strategies have not been well documented. This dearth of literature casts doubt on the appropriateness of these policies in different contexts, the level of investment that should be directed to ROS schemes as opposed to other possible uses and the best strategies of forming and reformulating the strategies. This research will investigate these issues by documenting the implementation of ROS initiatives across five Southern African nations and providing a critical analysis of the schemes using a multimethods approach to identify the strengths and limitations of these policies in practice. The research therefore aims to explore the historical development of ROS policies and evaluate the effectiveness and cost-effectiveness of ROS schemes. It also aims to 
understand the challenges in implementing ROS initiatives, with the aim of proposing a sustainable solution to global health workforce shortages.

In assessing these schemes and the polices underlying their development, the study will consider:

1. What are the motivations and the factors that inform the design of state sponsored educational initiatives used for addressing SHP shortages and/or maldistribution?

2. How are state sponsored educational initiatives evaluated and by whom?

3. Are the state-sponsored initiatives effective and costeffective in enhancing the availability of SHPs in specific areas of need?

4. Are the bursaries/scholarships being allocated in accordance with the policy?

5. In what respects do state sponsored educational initiatives for health professionals need to be reformulated to secure a sustainable health workforce solution?

\section{Research context}

This study will be conducted in Botswana, Eswatini, Lesotho, Namibia and South Africa. Except for Namibia and Lesotho, where the bursaries are administered by government agencies (Namibia Students Financial
Assistance Fund and the Lesotho National Manpower Development Secretariat), in all the other countries (Botswana, South Africa and Eswatini) they are administered directly by government ministries. The departments responsible in different countries include the nine provincial departments of health in South Africa; the Ministry of Tertiary Education in Botswana; the Ministry of Labour and Social Cecurity; and the Ministry of Public Service in Eswatini. In all these countries, the Ministry/ Department of Health is the main beneficiary and is thus either responsible for placement of graduates and/or for monitoring their progress and contribution.

\section{Methods and analysis}

The overall study is guided by a logic framework (figure 1).

\section{Design and setting}

The research questions will be answered through a multimethods approach of a policy review, a quantitative and two qualitative research studies. This multimethods approach will allow for the incorporation of various viewpoints and data from within the respective health systems. Data will be collected between 1 October 2020 and 31 December 2021. Table 1 summarises the research methods.
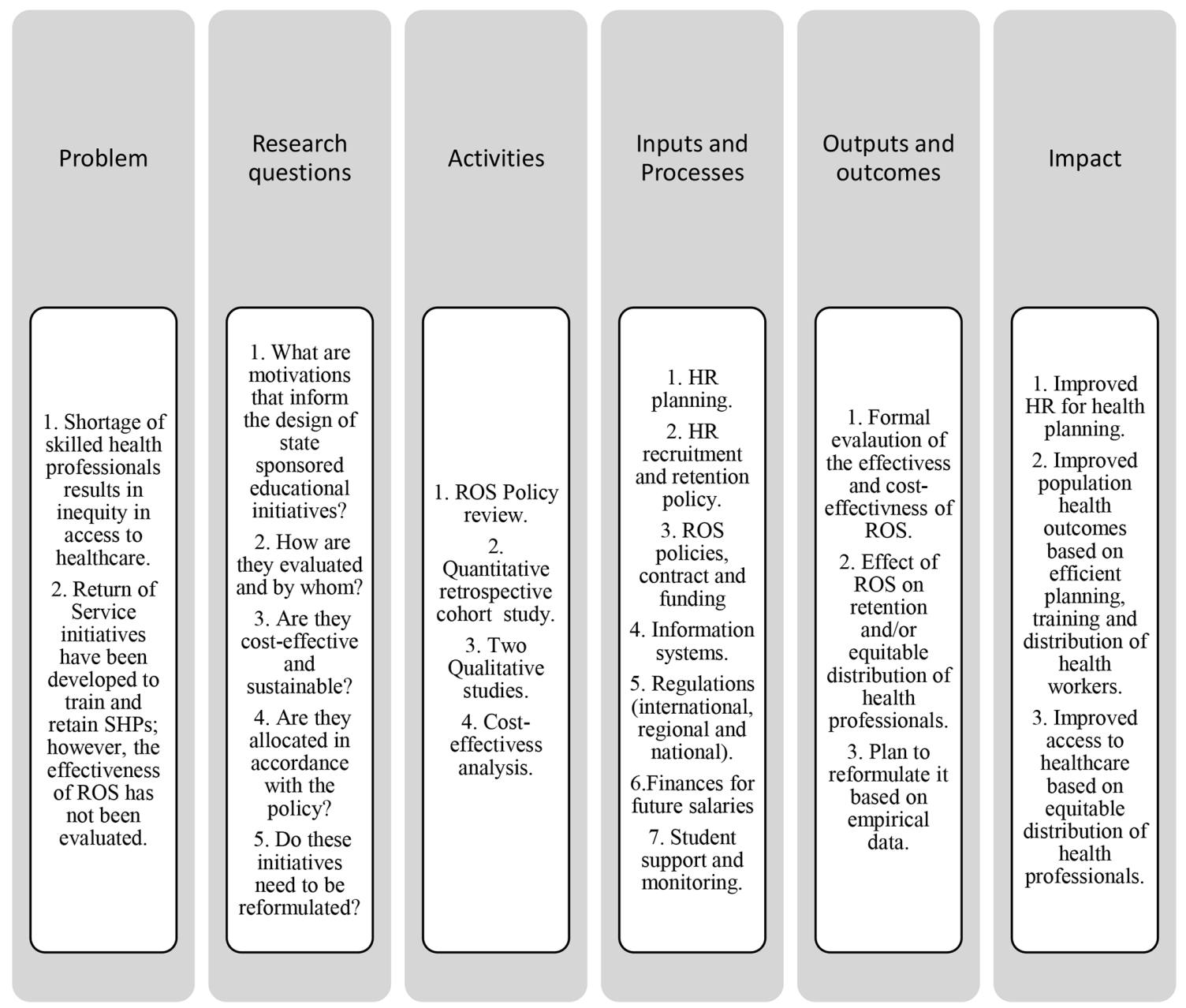

Figure 1 Logic framework. ROS, return-of-service; SHPs, skilled health professionals. 
Table 1 Research methods summary

\begin{tabular}{|c|c|c|c|c|c|}
\hline Study design & Objective & Data points & $\begin{array}{l}\text { Data collection } \\
\text { method }\end{array}$ & $\begin{array}{l}\text { Data collection } \\
\text { instruments }\end{array}$ & Analysis \\
\hline Policy review & $\begin{array}{l}\text { Understand the motivation, } \\
\text { aim and evolution of state- } \\
\text { sponsored educational } \\
\text { initiative policies in use } \\
\text { across the different } \\
\text { nations, their stated aims, } \\
\text { enforcement mechanisms } \\
\text { and target populations. }\end{array}$ & $\begin{array}{l}\text { 1. Policy context. } \\
\text { 2. Policy } \\
\text { implementation } \\
\text { processes. } \\
\text { 3. Policy Content. } \\
\text { 4. Policy Actors } \\
\text { (Stakeholders). }\end{array}$ & $\begin{array}{l}\text { 1. Request policy } \\
\text { documents from } \\
\text { custodians. } \\
\text { 2. Country-specific } \\
\text { national archive } \\
\text { sources. } \\
\text { 3. Literature review. }\end{array}$ & Data extraction tool. & $\begin{array}{l}\text { Narrative analysis } \\
\text { using the Walt } \\
\text { and Gilson policy } \\
\text { framework. }\end{array}$ \\
\hline $\begin{array}{l}\text { Quantitative } \\
\text { retrospective cohort } \\
\text { study }\end{array}$ & $\begin{array}{l}\text { 1. Assess effectiveness of } \\
\text { policies } \\
\text { 1. Demographic } \\
\text { characteristics of } \\
\text { policy recipients. } \\
\text { 2. The reach of the } \\
\text { policy. } \\
\text { 3. Proportion of } \\
\text { beneficiaries who } \\
\text { fulfil contractual } \\
\text { obligation. } \\
\text { 4. Proportion of } \\
\text { beneficiaries } \\
\text { retained beyond } \\
\text { contractual } \\
\text { obligation. } \\
\text { 5. Determine the } \\
\text { costs of the policy } \\
\text { and the costs per } \\
\text { SHP trained and } \\
\text { recruited. } \\
\text { 2. Evaluate sustainability } \\
\text { of the policies. }\end{array}$ & $\begin{array}{l}\text { 1. Beneficiary } \\
\text { demographic } \\
\text { characteristics } \\
\text { before and after } \\
\text { enrolment into } \\
\text { scheme. } \\
\text { 2. Selection } \\
\text { criteria used } \\
\text { that qualified } \\
\text { beneficiary into } \\
\text { scheme. } \\
\text { 3. University and } \\
\text { country where } \\
\text { beneficiary } \\
\text { studied. } \\
\text { 4. Name of } \\
\text { qualification } \\
\text { that beneficiary } \\
\text { studied for. } \\
\text { 5. Duration of } \\
\text { sponsorship. } \\
\text { 6. Duration of } \\
\text { studies. } \\
\text { 7. Completion } \\
\text { status of } \\
\text { qualification. } \\
\text { 8. Service record } \\
\text { (working } \\
\text { history) after } \\
\text { completion. } \\
\text { 9. Amount of } \\
\text { sponsorship per } \\
\text { beneficiary. } \\
\text { 10. Programme } \\
\text { cost relative to } \\
\text { Total budget. }\end{array}$ & $\begin{array}{l}\text { 1. Beneficiary } \\
\text { custodian } \\
\text { extracts and } \\
\text { triangulate data } \\
\text { from their internal } \\
\text { sources. } \\
\text { 2. Deidentified } \\
\text { data shared with } \\
\text { research team in } \\
\text { Microsoft Excel. }\end{array}$ & $\begin{array}{l}\text { 1. Export data from } \\
\text { Microsoft Excess } \\
\text { into customised } \\
\text { Microsoft Access } \\
\text { database. }\end{array}$ & $\begin{array}{l}\text { Survival analysis and } \\
\text { cost analysis. }\end{array}$ \\
\hline
\end{tabular}

\begin{tabular}{|c|c|c|c|c|c|}
\hline $\begin{array}{l}\text { Qualitative descriptive } \\
\text { study } 1\end{array}$ & $\begin{array}{l}\text { 1. Determine policy } \\
\text { makers' and } \\
\text { implementers' } \\
\text { interpretation, } \\
\text { experiences and } \\
\text { perceptions of ROS } \\
\text { policy. } \\
\text { 2. Describe policy makers' } \\
\text { and implementers' } \\
\text { perceived benefits and } \\
\text { challenges of ROS } \\
\text { policy. }\end{array}$ & $\begin{array}{l}3 . \\
4 . \\
5 . \\
6 . \\
7 . \\
8 .\end{array}$ & $\begin{array}{l}\text { Origins and } \\
\text { evolution of the } \\
\text { policy. } \\
\text { Custodian of the } \\
\text { policy. } \\
\text { Review of the } \\
\text { policy. } \\
\text { Decision } \\
\text { process. } \\
\text { Contract. } \\
\text { Process after the } \\
\text { completion of } \\
\text { studies. } \\
\text { Policy } \\
\text { Challenges. } \\
\text { Monitoring and } \\
\text { evaluation of the } \\
\text { policy. }\end{array}$ & $\begin{array}{l}\text { 1. Audio-recorded } \\
\text { semistructured, } \\
\text { virtual interviews } \\
\text { using interview } \\
\text { guide. } \\
\text { 2. Transcription of } \\
\text { interviews. }\end{array}$ & 1. Microsoft Teams. Thematic analysis. \\
\hline
\end{tabular}


Table 1 Continued

\begin{tabular}{|c|c|c|c|c|c|}
\hline Study design & Objective & Data points & $\begin{array}{l}\text { Data collection } \\
\text { method }\end{array}$ & $\begin{array}{l}\text { Data collection } \\
\text { instruments }\end{array}$ & Analysis \\
\hline $\begin{array}{l}\text { Qualitative descriptive } \\
\text { study } 2\end{array}$ & $\begin{array}{l}\text { 1. Determine alternative } \\
\text { mechanisms and } \\
\text { collaborations in the } \\
\text { monitoring of ROS } \\
\text { beneficiaries by } \\
\text { involving professional } \\
\text { regulatory bodies. }\end{array}$ & $\begin{array}{l}\text { 1. Relations with } \\
\text { ROS scheme } \\
\text { custodians. } \\
\text { 2. Knowledge of } \\
\text { state sponsored } \\
\text { ROS schemes. } \\
\text { 3. Process of } \\
\text { registration of } \\
\text { students to } \\
\text { council. } \\
\text { 4. Process of } \\
\text { registration } \\
\text { of health } \\
\text { professionals. } \\
\text { 5. Monitoring of } \\
\text { ROS schemes. } \\
\text { 6. Membership } \\
\text { renewal. } \\
\text { 7. Information } \\
\text { systems }\end{array}$ & $\begin{array}{l}\text { 1. Audio-recorded } \\
\text { semistructured, } \\
\text { virtual interviews } \\
\text { using interview } \\
\text { guide. } \\
\text { 2. Transcription of } \\
\text { interviews. }\end{array}$ & 1. Microsoft Teams. & Thematic analysis. \\
\hline
\end{tabular}

ROS, return-of-service; SHP, skilled health professional.

\section{Policy review}

An integrative policy review will be conducted to explore available ROS scheme policies, policy frameworks and relevant ROS documents (eg, memorandum of agreement). Historical and current policies will be requested from policy custodians and completed with manual searches of archives in the national libraries of the five countries. The Walt and Gilson triangle policy framework $^{1819}$ will be used as a framework for data extraction to get information on the context, content, processes and actors. This includes the determination of the policy objectives and rationale, government legislations and/ or regulations informing the policies, the monitoring and evaluation plan, enforcement mechanisms, policy evolution, processes used to define service needs, the recruitment and selection criteria, resourcing and the interaction of policy actors at different stages of the policy implementation cycle.

\section{Quantitative retrospective cohort study}

A quantitative retrospective cohort study of ROS scheme recipients for the period 2000-2010 will be conducted to: assess the criteria used to select beneficiaries, assess if the signed contracts specify the future service area, determine the service area (rural or urban) serviced by ROS beneficiaries stratified by profession and quantify the proportion of beneficiaries who fulfil their contractual obligations and those who remain beyond contractual obligations. Information will be sourced from multiple information systems and/or databases.

\section{Qualitative descriptive studies}

1. Semistructured group or individual interviews with senior health, education, ROS managing agency managers (where appropriate) and finance managers and/ policy makers (from all the selected Southern African countries) will be conducted to investigate the human resources needed over time and their views on ROS as a tool to recruit and retain health professionals.

2. Semistructured group or individual interviews will be conducted with health professionals' regulatory bodies in each of the countries to assess their abilities to monitor ROS initiative recipients and to assess their willingness to collaborate with ROS scheme funders (ie, policy makers).

\section{Participants and sampling}

Substudy 1 is a document and policy review, hence no sample size requirements.

The quantitative retrospective cohort study is a database review of all ROS beneficiaries who were funded at any time between the year 2000 and the year 2010 from the five countries. SHPs will be limited to medical doctors (including specialists), dentists, physiotherapists, occupational therapists, speech therapists, audiologists (including dually qualified audiologists and speech therapists) and pharmacists. It is important that the entire population for that period is studied as the main outcomes relate to the proportion of beneficiaries who fulfil their contractual obligations and those who serve beyond their contractual obligations. Sampling will therefore result in loss of valuable data. It is however anticipated that the study will draw \pm 14000 ROS beneficiaries from the database.

Qualitative study 1 will use purposive sampling to target all managers who can answer relevant questions on the ROS policy. In this sampling strategy, participants will be selected '... based on the researchers' judgement about what potential participants will be most informative'. ${ }^{20}$ 
The important issue will be to have the most qualified person answer the questions asked with the appropriate degree of authority. An email advertisement and communication will be sent to stakeholders through the offices of the accounting officers requesting potential participants to contact the research team for consent and scheduling of interviews. A guiding principle in qualitative research is to sample only until data saturation has been achieved. ${ }^{20}$ This aspect of the study will also not be limited by the sample size. Based on preliminary discussions, it is anticipated that in all the countries \pm 45 senior managers and policy makers will be interviewed mostly in groups.

Qualitative study 2 will target all those in management or governance of the Health Professions Council of South Africa; the Pharmacy Council of South Africa; Botswana Health Professions Council; Eswatini Medical and Dental Council; Lesotho Medical, Dental and Pharmacy Council; and the Health Professions Council of Namibia. It will also use purposive sampling techniques as described above. The aim is to have all technical expertise represented to have a better understanding of the regulatory framework and willingness of these bodies to collaborate with ROS funders in their monitoring strategies. Approximately 15 senior managers will be recruited to participate.

\section{Inclusion and exclusion criteria}

Material for the policy review will be sourced from all the five countries of interest and supplement with any published resources through an electronic search of the following databases: MEDLINE, PubMed, JSTOR, Science Direct, Embase, CINAHL, PsychInfo, Health Systems Evidence and PDQ-Evidence. Information found opportunistically through professional networks, media or email will be included if found to be relevant. Various policy documents including parliamentary Hansards, government archives, government and/or political party policy documents, legislation and regulations will be reviewed to understand the historical context, evolution and policy guidelines of ROS schemes. In addition, print media advertisements will be reviewed from the South African Medical Journal archives and from university prospectuses of the University of Cape Town and University of the Witwatersrand, the two oldest medical universities in Southern Africa. This information will facilitate an understanding of the nature of the schemes over time.

The quantitative retrospective cohort study includes records of participants who benefited from ROS schemes any time between 1 January 2000 and 31 December 2010. Such beneficiaries will be limited to the SHPs mentioned above.

Qualitative study 1 includes all policy makers and/or implementers involved with the administration of ROS schemes including the accounting officers. Participants in senior management/governance will be invited to participate in the study.

Qualitative study 2 includes all senior managers of regulatory bodies responsible for the registration of health professionals in the selected countries for the selected categories of health professionals.

\section{Data collection}

The policy review will use the Walt and Gilson triangle policy framework ${ }^{1819}$ for data extraction and categorised into four fields, namely: context, content, processes and actors. Data will be extracted using a customised data extraction tool online supplemental annexure A. Issues pertaining to context include sociopolitical, economic, demographic, environmental and health reasons for the policy development; content includes policy rationale, monitoring and evaluation plan, presence of policy review date, presence of preceding policy term, if policy was reviewed on predetermined date, recruitment and selection criteria, contractual responsibilities of beneficiaries, enforcement mechanisms framework, education costs covered by funding, details of programme funding and resourcing and the proportion and composition of skills mix required to meet population health needs; information on actors includes, a description of characteristics of potential beneficiaries and any stakeholders identified; processes include guide or framework used for policy development; stakeholder engagement or participation and number of times policy has been revised; and prioritisation or weighting of service areas and linkage of ROS contract award to future salary needs.

The quantitative retrospective cohort study reports on the criteria used to identify ROS beneficiaries, academic programme of study, identified future service area, duration of study, presence of a valid legal contract(s) and its/ their duration, fulfilment of service obligation, retention in service area beyond obligatory period, practice history and programme cost per candidate. Sociodemographic characteristics such as sex, income level and ethnic group will be collected to assess the predictors of retention. These variables will also be used to identify ROS scheme beneficiary selection criteria and to match it with the available information on the database. Where affirmative action has been used as a criterion, for example, certain participants could be scored higher than others based on their race, the study will evaluate how the final beneficiary list reflects this factor and which of the criteria (eg, academic grades and rurality) is weighted more than another.

The qualitative studies will use English semistructured interviews (individual and group discussions) and use open-ended questions aided by interview guides '.. with early questions being more exploratory' (online supplemental annexure B) ${ }^{21}$ For ROS initiative administrators, initial questions will focus on the policy origin and policy context. Subsequent questions will explore policy decision processes, reviews, challenges, processes of beneficiary employment and monitoring and evaluation plans.

Interviews with senior health, education, ROS managing agency managers (where appropriate) and finance managers and/policy makers (from all the selected Southern African countries) will be held to investigate 
the human resource needs over time (burden of disease, human resource skills mix, distribution of SHPs and the human resource for health planning framework), policy intention, development, and monitoring mechanisms, budget allocation for SHP education as a proportion of total health expenditure over time, health workforce budget over time (adjusting for inflation), proportion of health workforce budget over time (adjusting for inflation) and perceptions on the effectiveness of ROS schemes. The latter will get their thoughts on broader issues with the policies, such as reasons for their success or failure and so on.

Similarly, for the regulatory bodies, the interviews will seek to understand the relations regulatory bodies have with ROS scheme funders (online supplemental annexure C). Subsequent questions will explore the process flow of registration of professionals (during studies and employment), renewal of membership, the information system(s) used and whether they might be open to integration of their information systems with ROS managers. This aspect of the study will therefore assess the feasibility of a gatekeeping mechanism; possibilities of an interoperable information system between the funders; the human resource information system; and the regulatory practice information system.

This research is being conducted during the COVID-19 pandemic when governments have implemented certain restrictions to limit transmission, including the closing of borders and limiting international travel. ${ }^{22}$ These uncertainties and restrictions therefore necessitate an innovative approach to data collection in a multisite research project for a mixed-methods study. Qualitative research interviews will either be virtual, face to face or both depending on the feasibility to travel. In the case of virtual interviews, codes and passwords for the interview will be sent to each individual (single user access) or group access point to ensure privacy.

\section{Operational definition of major study variables}

Duration of funding will consider the full duration of in-kind or funding support paid to beneficiaries from ROS schemes.

Service need will describe the process used to either justify the recruitment of a beneficiary from a specific area of residence or placement of beneficiary in a specific service area.

Skills mix refers to the proportional distribution of the different categories of health professionals (including doctors, nurses, pharmacists, rehabilitation professionals and so on).

ROS will be assessed through analysis of the service history and compared with the duration of funding received.

\section{Data management and analysis}

Narrative and critical synthesis of policies and the policy frameworks used will be undertaken for the policy review. Structured analysis will be conducted to ensure reliability of the process. Variables extracted and reported on include the conception (research and sociopolitical basis for policy), inception (date of launch or version number and policy framework) and evolution of the policy over time, policy aim, beneficiary recruitment process and selection criteria, skills mix defined by policy, defined service area, details of funding and budgetary implications per year, policy review date and whether the policy was reviewed on stated date, responsibilities of beneficiaries and responsibilities of government, policy monitoring and evaluation processes and so on.

A specially designed Microsoft Access database template will be used to capture data from the ROS beneficiary databases (online supplemental annexure D). Quantitative data will be analysed using STATA V.16. Categorical variables will be summarised using graphs and frequency tables. Numerical data will be summarised using parametric or non-parametric statistics depending on the normality of the distribution. Normality of numerical data will be explored using the Shapiro Wilk test and/or boxand-whisker plot. Numerical variables will be summarised using the mean, SD and range if normally distributed and summarised using the median and IQR if not normally distributed. The analysis of variance test (analysis of variance) or Kruskal-Wallis test will be used to compare the mean or median duration of service by country and/or province depending on normality of the distribution. These will then be followed by use of the relevant twosample t-test or Wilcoxon rank-sum test (Mann-Whitney $\mathrm{U}$ test) to determine differences in means or medians between any two comparisons. Survival analysis will be conducted using Kaplan-Meier survival estimates to determine the duration of service and fulfilment of contractual obligations. The HRs will be used to determine the predictors of retention by practice area (rural and underserved or urban), sociodemographic characteristics and the university or country of study. The $95 \%$ CI will be used for the precision of estimates. The level of significance will be $p$ value $\leq 0.05$.

Collected cost data will be used to evaluate the resources invested in the schemes and the proportion of the total health budget spent on ROS schemes. Overall costs will be estimated for each programme and a cost per beneficiary trained and retained will be calculated. These will be based on the direct cost of funding granted to the beneficiary over the duration of the funding and other programme costs extracted from national databases.

Semistructured group and individual interviews will be audio-recorded and transcribed by a contracted transcription service for the qualitative studies. All data will be deidentified. The transcripts will be analysed by all authors using an inductive approach to thematic content analysis. This is an approach where codes are developed after data transcription and not basing them on preconceived assumptions or frameworks. ${ }^{23}$ Interview coding will be organised using NVivo V.12. Two peer researchers will help with the coding and categorisation of the '.. 
data as confirmation that there is a degree of shared interpretation'. ${ }^{24}$

\section{Integration of the data}

First, the policy evolution and evaluation strategy as stated in policy documents will be compared descriptively with the responses of policy makers. Second, the selection criteria of beneficiaries as described in policy document(s) will be descriptively compared with responses of policy makers and information sourced during quantitative component of the study to assess criteria used to select an individual beneficiary. Third, the policy objectives as stated in policy documents will be compared with the responses of policy makers and the attainment of these objectives as analysed in the quantitative substudy. Fourth, information sourced from policy makers on monitoring mechanisms will be triangulated with information sourced from regulatory bodies to assess possibilities of collaboration. Broadly, with the policy review and qualitative components of the study there to deepen the quantitative study, the substudies will complement each other.

\section{Limitations}

Even though care will be taken to limit systematic biases in data collected and analyses performed, our work will be limited by the availability and quality of programme data and the availability of participants. All efforts will be taken to mollify the impact of these factors. We will conduct individual or group interviews based on the availability of participants. Working in collaboration with national and subnational authorities, data will be extracted from administrative data collections on all bursary recipients, providing access to the best available data for our research questions. This will be triangulated by both qualitative and quantitative bespoke data collected through this study as described to provide the fullest picture possible on the operation and income of these schemes. Administrative data will be extracted by local collaborators in each nation and will be assisted by trained research assistants if necessary.

\section{Patient and public involvement}

Patients and members of the public were not involved in the design of this study since they will not be recruited to participate in the study.

\section{ETHICS AND DISSEMINATION}

Ethics approval for this study was obtained from the Human Research Ethics Committees of the University of New South Wales (HC200519), Australia; South Africa and Lesotho: Walter Sisulu University, South Africa (065/2020); Botswana: the Health Research and Development Division (HPDME 13/18/1); Eswatini: Eswatini Health and Human Research Review Board (SHR302/2020); and Namibia: National Commission on Research Science and Technology (SK001). Research access approval has been attained from all the study sites. The policy review has no human participants and therefore has no need for consent. Similarly, a waiver of consent was sought for the quantitative retrospective cohort study due to the fact that it is a database review, and it would not be possible to seek consent from the ROS beneficiaries. Furthermore, this aspect of the study will not cause any harm to the beneficiaries as no names or identities will be collected from the database. Permission to access ROS beneficiary data will be sought from the accounting officers.

We will seek written informed consent from participants for the qualitative studies. Participants will be recruited through written advertisements or email invitations sent to the accounting officers. The advertisement and/or invitation will ask interested managers to contact the research team if they are interested in participating. All potential participants will be sent individual emails through the office of the accounting officer.

Significance: this study will evaluate the effectiveness and cost-effectiveness of ROS schemes. Furthermore, it will provide insights into the implementation of ROS initiatives and seek to ensure that health budgets benefit those segments of the population most in need. Outcomes from this study will help develop interventions for the improvement in SHP distribution in underserved areas, not just in the study sites but globally through the sharing of lessons drawn from this study. Participating governments will also benefit as these findings will serve as an evaluation by an independent panel. Recommendations emanating from this study will help ensure efficiency of ROS schemes and could lead to policy makers reviewing a host of other related policies to improve practice and extend the provision of targeted health services.

Results will be published in peer-reviewed journals, an academic thesis, technical reports, presented at relevant conferences and communicated via professional networks. Findings will also be shared with and/or presented to all participating governments and institutions.

\section{Author affiliations}

${ }^{1}$ The George Institute for Global Health, University of New South Wales, Sydney, New South Wales, Australia

${ }^{2}$ Institute for Global Health, University College London, London, UK

${ }^{3}$ The George Institute for Global Health India, New Delhi, India

${ }^{4}$ Law, University of New South Wales, Sydney, New South Wales, Australia

Twitter Sikhumbuzo Mabunda @SikhumbuzoAMab1

Acknowledgements The authors would like to acknowledge support received from officials of all the participating country ministries, government agencies and health professional regulatory bodies for their assistance.

Contributors SM conceived the research, completed the first draft of the manuscript, incorporated and addressed feedback from the coauthors, liaised with stakeholders and sought ethical approval from participating countries. BA edited and commented on versions of the manuscript. RJ cosenior author, led ethics application processes at the University of New South Wales, commented on versions of the manuscript, edited versions of the manuscript and signed off on the final version. $A D$ cosenior author, commented on versions of the manuscript, edited versions of the manuscript and signed off on the final version. All authors read and approved the final manuscript. 
Funding This work was supported by the University of New South Wales Scientia Fellowship (Scientia 2019).

Competing interests None declared.

Patient consent for publication Not required.

Provenance and peer review Not commissioned; externally peer reviewed.

Supplemental material This content has been supplied by the author(s). It has not been vetted by BMJ Publishing Group Limited (BMJ) and may not have been peer-reviewed. Any opinions or recommendations discussed are solely those of the author(s) and are not endorsed by BMJ. BMJ disclaims all liability and responsibility arising from any reliance placed on the content. Where the content includes any translated material, BMJ does not warrant the accuracy and reliability of the translations (including but not limited to local regulations, clinical guidelines, terminology, drug names and drug dosages), and is not responsible for any error and/or omissions arising from translation and adaptation or otherwise.

Open access This is an open access article distributed in accordance with the Creative Commons Attribution Non Commercial (CC BY-NC 4.0) license, which permits others to distribute, remix, adapt, build upon this work non-commercially, and license their derivative works on different terms, provided the original work is properly cited, appropriate credit is given, any changes made indicated, and the use is non-commercial. See: http://creativecommons.org/licenses/by-nc/4.0/.

\section{ORCID iDs}

Sikhumbuzo Mabunda http://orcid.org/0000-0001-9458-3742

Blake Angell http://orcid.org/0000-0002-7188-7740

Rohina Joshi http://orcid.org/0000-0002-3374-401X

\section{REFERENCES}

1 World Health Organization. Monitoring the building blocks of health systems: a Handbook of indicators and their measurement strategies. Geneva, Switzerland: WHO Document Production Services, 2010. https://www.who.int/healthinfo/systems/WHO_MBHSS_2010_full_ web.pdf

2 Frenk J. The global health system: strengthening National health systems as the next step for global progress. PLoS Med 2010;7:e1000089.

3 Management Sciences for Health. Health systems in action: an eHandbook for leaders and managers. Cambridge: MA: Management Sciences for Health, 2010. https://www.msh.org/resources/healthsystems-in-action-an-ehandbook-for-leaders-and-managers;

4 Mabunda SA, Angell B, Yakubu K, et al. Reformulation and strengthening of return-of-service (ROS) schemes could change the narrative on global health workforce distribution and shortages in sub-Saharan Africa. Fam Med Community Health 2020;8:e000498.

5 Asamani JA, Akogun OB, Nyoni J, et al. Towards a regional strategy for resolving the human resources for health challenges in Africa. BMJ Glob Health 2019;4:e001533.

6 South African National Department of Health. 2030 human resources for health strategy: investing in the health workforce for universal health coverage. Pretoria: Government Printers, 2020.

7 The World Bank. Global health workforce statistics, OECD, supplemented by country data. Geneva, Switzerland, 2018. https:// data. worldbank.org/indicator/SH.MED.NUMW.P3?locations=BW-SZLS-NA-ZA-ZG

8 World Health Organization. Global strategy on human resources for health: workforce 2030. Geneva, Switzerland: WHO, 2016. https:// www.who.int/hrh/resources/global_strategy_workforce2030_14_ print.pdf?ua=1;

9 South African National Department of Health. Human resources for health South Africa: HRH strategy for the health sector: 2012/13 2016/17 Health, ed. Pretoria, South Africa, 2013. https://www.gov.za/ sites/default/files/gcis_document/201409/hrhstrategy0.pdf;

10 Hamilton K, Yau J. The global tug-of-war for health care workers. The Online Journal of the Migration Policy Institute, 2004.

11 Statistics South Africa. People of South Africa: population census, 2016. SA S, ed. Pretoria, South Africa, 2017. http://www.statssa.gov. $\mathrm{za} /$;

12 Ross AJ, Couper ID. Rural scholarship schemes a solution to the human resource crisis in rural district hospitals? SAFP 2004;46:5-6.

13 Lehmann U, Dieleman M, Martineau T. Staffing remote rural areas in middle- and low-income countries: a literature review of attraction and retention. BMC Health Serv Res 2008;8:19.

14 Grobler L, Marais BJ, Mabunda S. Interventions for increasing the proportion of health professionals practising in rural and other underserved areas. Cochrane Database Syst Rev 2015;6:Cd005314.

15 Donda BM, Hift RJ, Singaram VS. Assimilating South African medical students trained in Cuba into the South African medical education system: reflections from an identity perspective. BMC Med Educ 2016;16:281.

16 Bärnighausen T, Bloom DE. Financial incentives for return of service in underserved areas: a systematic review. BMC Health Serv Res 2009;9:86.

17 Bärnighausen T, Bloom DE. "Conditional scholarships" for HIV/ AIDS health workers: educating and retaining the workforce to provide antiretroviral treatment in sub-Saharan Africa. Soc Sci Med 2009;68:544-51.

18 Mokitimi S, Schneider M, de Vries PJ. Child and adolescent mental health policy in South Africa: history, current policy development and implementation, and policy analysis. Int $J$ Ment Health Syst 2018;12:36.

19 van de Pas R, Kolie D, Delamou A, et al. Health workforce development and retention in guinea: a policy analysis post-Ebola. Hum Resour Health 2019;17:63.

20 Moser A, Korstjens I. Series: practical guidance to qualitative research. Part 3: sampling, data collection and analysis. Eur J Gen Pract 2018;24:9-18.

21 Lawn S, McMahon J. The importance of relationship in understanding the experiences of spouse mental health carers. Qual Health Res 2014;24:254-66.

22 Ammar A, Chtourou H, Boukhris O, et al. COVID-19 home confinement negatively impacts social participation and life satisfaction: a worldwide multicenter study. Int J Environ Res Public Health 2020;17. doi:10.3390/ijerph17176237. [Epub ahead of print: 27 Aug 2020].

23 Terry G, Hayfield N, Clarke V. Thematic analysis. In: Willig C, Rogers W, eds. The SAGE Handbook of qualitative research in psychology. London: SAGE Publications Ltd, 2017: 17-37.

24 Ruhl K. Qualitative research practice. A guide for social science students and researchers, 2004 